\title{
A PRESERVAÇÃO DA CULTURA QUILOMBOLA INTRA E INTERGERACIONAL
}

\author{
Rúbia Mara Ferreira de Alvarenga iD1 \\ Angela Maria Caulyt Santos da Silva iD2
}

\section{Resumo}

Analisou-se a preservação da cultura na comunidade tradicional quilombola Araçatiba, originária de uma antiga fazenda do século XVII, no município de Viana, Região Metropolitana de Vitória / ES, a partir da percepção da mulher quilombola sobre a transmissão intra e intergeracional, nos processos sociais da educação familiar informal e da cultura quilombola. Inspirou-se em Norbert Elias, nos conceitos de relação entre indivíduo e sociedade, relações de poder, figuração/configuração, identidade, afetos e processos sociais de longa duração: educação e cultura. E dada à natureza e ao contexto do objeto investigado cultura quilombola -, agregou-se na fundamentação teórica conceitos de cultura, identidade e educação, em uma perspectiva epistemológica negra, por esta conceber a metodologia decolonial/descolonial que discute: racismo, formação de quilombos no Brasil, comunidades quilombolas na atualidade, Educação para as Relações Étnico-Raciais e outros. Pesquisa qualitativa, bibliográfica, documental e empírica com entrevista de campo com 10 mulheres: cinco entre 19 e 38 anos, e cinco entre 53 e 85 anos, cujo acesso às participantes ocorreu por meio de liderança local. Almejava-se entrevistar 10 mulheres acima de 45 anos, entretanto, este quantitativo não foi encontrado. Os dados foram analisados a partir da técnica Análise de Conteúdo. A vivência dessas mulheres em sua organização social, política e territorial é legado na transmissão intra e intergeracionais. Conclui-se que as vivências, participações e contribuições para a resistência cultural e territorial do povo quilombola se presentificam nas narrativas do cotidiano dessas mulheres, protagonistas em sua comunidade.

Palavras-chave: População tradicional; Mulheres quilombolas; Resistência; Cultura; Educação informal.

\section{THE PRESERVATION OF INTRA AND INTERGERATIONAL QUILOMBOLA CULTURE}

\section{Abstract}

The preservation of culture was analyzed in the traditional quilombola community Araçatiba, originating from an old farm from the 17th century, in the municipality of Viana, Metropolitan Region of Vitória / ES, from the perception

\footnotetext{
${ }^{1}$ Mestre em Políticas Públicas e Desenvolvimento Local e Assistente Social pela Escola Superior de Ciências da Santa Casa de Misericórdia de Vitória - EMESCAM. Graduanda em História pela Universidade Federal do Espírito Santo (UFES). ${ }^{2}$ Doutora e Mestre em Educação, Especialista em Políticas e Práticas Sociais em Saúde e Assistente Social pela Universidade Federal do Espírito Santo (UFES). Especialista em Terapia Familiar pela Crescent. Professora Adjunta do Mestrado em Políticas Públicas e Desenvolvimento Local da Escola Superior de Ciências da Santa Casa de Misericórdia de Vitória - EMESCAM.
} 
of quilombola women about intra and intergenerational transmission, in the processes aspects of informal family education and quilombola culture. He was inspired by Norbert Elias, in the concepts of relationship between individual and society, power relations, figuration / configuration, identity, affections and longterm social processes: education and culture. And given the nature and context of the investigated object - quilombola culture -, it was added in the theoretical foundation, concepts of culture, identity and education, in a black epistemological perspective, for this conceiving the decolonial / decolonial methodology that discusses: racism, formation quilombos in Brazil, quilombola communities today, Education for Ethnic-Racial Relations and others. Qualitative, bibliographic, documentary and empirical research with field interview to 10 women: five between 19 and 38 years old and five between 53 and 85 years old, whose access to the participants occurred through local leadership. It was aimed at interviewing 10 women over 45 years old, however this amount was not found. The data were analyzed using the Content Analysis technique. The experience of these women in their social, political and territorial organization is inherited in intra and intergenerational transmission. It is concluded that the experiences, participations and contributions to the cultural and territorial resistance of the quilombola people are present in the daily narratives of these women, protagonists in their community.

Keywords: Traditional population; Quilombola women; Resistance; Culture; Informal education.

\section{Introdução}

Nesta pesquisa objetivou-se analisar a preservação da cultura em uma comunidade tradicional quilombola, na percepção das mulheres, sobretudo a partir da transmissão intra e intergeracional em tessituras afetivas, por meio dos processos sociais da educação familiar informal e da cultura quilombola.

Para tanto, se tornou necessário construir uma aproximação históricocultural, com a teoria de Norbert Elias, devido este sociólogo contribuir com categorias de análise para esta pesquisa, ao apresentar conceitos elementares: a relação entre indivíduo e sociedade, relações de poder, figuração/configuração, identidade, afetos e processos sociais de longa duração: educação e a cultura.

Contudo, por Norbert Elias ser europeu e ter construído sua teoria a partir do território da Europa, por conseguinte, em lugares e tempos distantes do tema aqui pesquisado - cultura quilombola - fez-se necessário tecer paralelo dos conceitos sociológicos elisianos, anteriormente citados, com aporte teórico ao se adicionar autores que estudam a epistemologia negra da descolonização, sistematizam e produzem conhecimento, nesta perspectiva, acerca do tema e questões a ele relacionadas como: racismo, formação de quilombos no Brasil, comunidades quilombolas na atualidade e Educação para as Relações ÉtnicoRaciais, entre outros.

Destaca-se que o estudo da transmissão da cultura quilombola, intra e intergeracional, decorre como parte da luta contra o racismo estrutural e da 
negação da cultura negra pela cultura europeia hegemônica. Instaurada assim, uma relação de poder, entre brancos e negros.

É necessário o estudo da História Africana, com ênfase na desconstrução e na descolonização, a exemplo das Leis 9.394/1996, 10.639/2003 e 11.645/ 2008, que têm sob o prisma legal a premissa de, no país onde a expressa maioria é afrodescendente, que o Estado valorize a potência da cultura e da herança negras expressas em várias manifestações culturais - técnicas agrícolas, culinária, danças, músicas, credos, tradição oral e outras, - presentes no patrimônio cultural brasileiro material e imaterial.

Para a compreensão do processo, torna-se relevante destacar Bernardino-Costa e Grosfoguel (2016) que alertam: "Os sujeitos coloniais que estão nas fronteiras - físicas e imaginárias - da modernidade não eram e não são seres passivos. Eles podem tanto se integrar ao desenho global das histórias locais que estão sendo forjadas como podem rejeitá-las". Esses autores ainda afirmam que: "É nessas fronteiras, marcadas pela diferença colonial, que atua a colonialidade do poder, bem como é dessas fronteiras que pode emergir o pensamento de fronteira como projeto decolonial" (BERNARDINO-COSTA; GROSFOGUEL, 2016, p. 18). Nesta mesma linha de pensamento, Martins (2020) corrobora ao afirmar que:

[...] temos a possibilidade de construir outros enunciados e "sujeitos de saber", na perspectiva de produzir possibilidades de resistência aos modelos explicativos globais, hegemônicos, eurocêntricos, considerando a potência dos saberes tradicionais, que se mantêm secularmente (MARTINS, 2020, p. 138).

Cita-se que "a perspectiva negra decolonial brasileira [...] dá relevância aos saberes e às práticas afro-brasileiras emaranhadas em todos nós, inclusive nas pessoas brancas, nos vários grupos de imigrantes e seus descendentes e nos povos indígenas brasileiros" (GOMES, 2018, p. 249).

Nessa perspectiva destaca-se que os quilombos - desde a sua origem possuíam forma organizacional, com princípios culturais, econômicos e políticos.

O quilombola era um membro da comunidade escrava, ele frequentemente circulava entre a escravidão e a liberdade, ajudando toda a coletividade dos escravos a redefinir, perante os senhores, novos espaços de barganha. Ser quilombola era um item do "currículo" de escravo e, para que este não se tornasse permanente, muitos senhores amenizavam as brutalidades, o que se tornou especialmente verdadeiro em certas conjunturas políticas. Em geral, na origem da fuga para a formação de quilombos estava exatamente a intransigência de senhores que desrespeitavam certos ganhos - que os escravos já consideravam direitos -, permitindo o afloramento de impasses insuperáveis dentro da rotina da fazenda e da casa (REIS, 1996, p.197-198). 
Ainda no período vigente, é mantida essa identidade de preservação da cultura, dos bens materiais e imateriais, por meio das transmissões intra e intergeracionais às novas gerações, proporcionando trocas de fazeres e saberes.

Isso posto, compreende-se que é através da mulher quilombola que a resistência matriarcal se presentifica por longo período. Nesse legado de transmissão cultural, a importância da mulher é ainda mais forte, tanto na constituição da comunidade como na sua preservação, desde as heroínas do passado, que lutavam por liberdade, até as "anônimas" de hoje. Desta forma, valorizar a vivência da mulher quilombola significa assinalar a importância da questão racial conjecturando o processo histórico desde o período colonial até o século XXI, com uma nova roupagem social trajada de reminiscência.

O legado da memória e da cultura do povo quilombola acontece principalmente na prática da vivência cotidiana. A transmissão de conhecimento das expressões culturais é essencial na/para a resistência dessas mulheres:

E essa história a ser escrita, ou história para o presente, é a história da construção de uma identidade respectiva, uma identidade que se deve construir a partir da igualdade, que é uma categoria que torna crível o diálogo. Uma igualdade que não significa similitude, monotonia, uniformidade, porque só as diferenças tornam interessantes os diálogos (VILANOVA, 1994, p. 56).

No decorrer da discussão sobre o conceito de relações humanas, vale destacar que:

O estilo de coexistência nas relações humanas é marcado pelo controle geral dos afetos. No decurso do processo civilizador, um número cada vez maior de funções relativas ao controle das pessoas, antes exercidas por pequenos grupos, vai sendo transferido para Estados altamente centralizados e cada vez mais urbanizados. A mobilidade social e espacial amplia e as pessoas tornam-se menos dependentes da família, parentes ou grupos locais próximos no sentido da proteção física, da ajuda e do controle. Quanto maior a complexidade das sociedades nacionais, maior o número de opções para o indivíduo, maior o fluxo de contatos humanos, mais pesadas as exigências emocionais de uns aos outros e maiores as cobranças por autonomia (XAVIER, 2020, p. 213).

É importante compreender dados descritivos imbricados nas relações humanas como: pessoas, lugares, vivência do contato do pesquisador com o seu estudo, assim entendendo-se os fenômenos diante das subjetividades. Segundo Elias (2006), a definição das expressões e da figuração se diferencia de outras definições teóricas dentro da sociologia, por abranger, de modo expressivo, os seres humanos em seu processo de formação.

Por conseguinte, torna-se relevante destacar Munanga (2005) que adverte: "É obrigação do Estado a proteção das manifestações culturais das culturas populares, indígenas e afro-brasileiras, bem como dos demais grupos 
participantes de nosso processo civilizatório. Essa obrigação deve refletir-se também na educação" (MUNANGA, 2005, p. 9).

Existem expressões de figuração de plantas, animais, estrelas etc., mas somente os seres humanos formam essas expressões de figurações ou configurações uns com os outros. O modo de viver em grupos de diversos tamanhos é único e sempre codeterminado pela transmissão de conhecimento que é passado de geração em geração. Dessa forma, aprofunda-se por meio desse caminho singular no mundo da simbologia específica, de uma expressão de figuração, já existente da natureza humana.

O conceito de configuração pode fazer referência a relações mais ou menos estáveis, pacíficas e amigáveis entre as pessoas, assim como a relações hostis e prestes a se romper. Por isso, Elias não se limita a estudar as formações sociais estabelecidas, mas vai em busca de desequilíbrios, de situações de violência, de solidão e morte (COSTA, 2017, p. 40).

A autonomia correspondente dos processos sociais se insere na continuidade do enlace de ações diversas do pensamento, sensações únicas de grupos humanos. O seguimento intergeracional do ser humano e sua subsistência como um conjunto sucessivo, em seus aspectos econômicos como autorregulação, necessita uma transmissão de conhecimento, com a ajuda dos símbolos linguísticos. Os processos sociais, que tendem a serem mais longos, permitem reconhecer constantemente e de modo visível a ruptura de um estágio do processo para o outro, por meio de um deslocamento de poder em suas variações de mudanças (ELIAS, 2006). Nesta linha de pensamento, Xavier (2020) ressalta a coerção dos afetos em Elias:

[...] a dinâmica de contenção dos afetos é, portanto, responsável pela conformação dos comportamentos, sentimentos, preferências, repulsas, pensamentos e objetivos dos indivíduos. Noutros termos, amor, medo, vergonha, constrangimento dentre outras emoções humanas e dores sociais, experimentadas no interior das figurações, constituem as fontes da individualização das pessoas no processo civilizador (XAVIER, 2020, p. 214).

Concebe-se que os afetos impulsionam os quilombolas à superação de estigmas mediante o processo de descolonização, tornando-os mais empoderados em suas relações sociais. A seguir, apontam-se os procedimentos éticos e metodológicos, as participantes mulheres quilombolas e a caracterização do locus da pesquisa.

\section{Metodologia}

A pesquisa é de natureza qualitativa, bibliográfica, documental e empírica e analisa a preservação da cultura em uma comunidade tradicional quilombola com ênfase nos processos sociais da educação familiar informal e da cultura, com enfoque na percepção das mulheres quilombolas, por meio de narrativas. 
Nesta pesquisa respeitaram-se os aspectos éticos das Resoluções $466 / 2012$ e 510/2016 do Conselho Nacional de Saúde (CNS), cujo projeto obteve Parecer Consubstanciado pelo Comitê de Ética em Pesquisa (CEP). Constitui-se de um recorte da pesquisa de dissertação de mestrado, defendida em 2019.

Conforme dito na Apresentação, se apoiou em aproximações à teoria de Norbert Elias para fundamentar as discussões acerca da temática, sobretudo com os conceitos: a relação entre indivíduo e sociedade, relações de poder, figuração/configuração, identidade, afetos e processos sociais de longa duração: educação e a cultura. E dada à natureza e ao contexto do objeto investigado cultura quilombola -, agregou-se na fundamentação teórica os conceitos de cultura, identidade e educação, em uma perspectiva epistemológica negra, por esta conceber a metodologia decolonial/descolonial que discute: racismo, formação de quilombos no Brasil, comunidades quilombolas na atualidade, Educação para as Relações Étnico-Raciais e outros.

O locus dessa pesquisa é a Comunidade Quilombola de Araçatiba, originária de uma antiga fazenda do século XVII, localizada no município de Viana, na Região Metropolitana de Vitória, tendo limites com os municípios capixabas: Guarapari, Vila Velha, Domingos Martins e Cariacica (NEEPES/ENSP/FIOCRUZ, 2009).

Essa Comunidade foi fundada pelos jesuítas espanhóis, que encontraram os tupiniquins - os primeiros habitantes - e os catequizaram, obrigando-os a trabalhar na grande fazenda de Araçatiba, nos engenhos de açúcar e na construção da Igreja Nossa Senhora da Ajuda, em 1665. Abriram também o canal do Rio Jacarandá, por onde faziam o transporte da produção agrícola para Vitória (INSTITUTO BRASILEIRO DE ANÁLISES SOCIAIS E ECONÔMICAS; FURNAS CENTRAIS ELÉTRICAS SA; COMITÊ DE ENTIDADES NO COMBATE À FOME E PELA VIDA, 2006).

A Comunidade fica a cerca de $20 \mathrm{~km}$ da sede de Viana e a $30 \mathrm{~km}$ do centro de Vitória. Sua população é composta por aproximadamente 200 famílias ou cerca de 800 moradores, a maioria descende de quilombolas que lutam tanto pelo reconhecimento de seu legado cultural quanto pela titulação de seu território tradicional. As terras que Ihes foram legadas eram em torno de 20 hectares, que gradativamente foram ocupadas por fazendeiros, restando tamanho insuficiente para a manutenção de seu modo de vida tradicional, o que obriga a maioria dos quilombolas a buscar emprego fora da comunidade, seja em Viana ou em outros municípios da Grande Vitória. Nos primórdios, ocupavam-se da cultura da cana-de-açúcar, em seguida pela cultura da mandioca e a produção de farinha, quando se ocupavam das atividades da fazenda. A agricultura foi sendo substituída por pastos para o gado, e os quilombolas se viram forçados a vender sua força de trabalho na sede do município e em outras cidades. Frente ao exposto, menos de $10 \%$ da população local ainda hoje cultiva em seus lotes. Atualmente com o êxodo da população, ocorre por um lado, pela pouca disponibilidade de terras e por outro lado, pela falta de empregos na região. Alia-se a tais fatos que garantir o território original 
é importante fator de manutenção da coesão social da comunidade e de fortalecimento de sua identidade diferenciada (NEEPES/ENSP/FIOCRUZ, 2009).

A aproximação com o locus da pesquisa foi intermediado pela líder da Cooperativa das Mulheres Quilombolas de Araçatiba. A princípio, a pesquisa teria como critério de inclusão 10 mulheres na faixa etária superior a 45 anos, porém, durante a coleta de dados empíricos, a realidade foi diferente diante da expectativa metodológica, por não haver, naquela comunidade, a quantidade de mulheres quilombolas acima dos 45 anos.

Conforme o planejado, mediante tal restrição, necessitou-se limitar o número de participantes por faixa etária mediante o que a realidade oferecia, ou seja, foram entrevistadas cinco mulheres quilombolas no primeiro grupo - da faixa etária definida inicialmente, completando com o número de cinco participantes para compor o segundo grupo - da faixa etária de 19 a 38 anos.

$\mathrm{Na}$ coleta de dados foram utilizados a técnica de entrevista e formulário semiestruturado de entrevista. Participaram da pesquisa 10 mulheres nativas, cinco na faixa etária acima de 45 anos e cinco do grupo etário de 19 a 38 anos, todas domiciliadas na Comunidade Quilombola Araçatiba, que foram nomeadas com pseudônimos em homenagem às mulheres negras brasileiras que lutaram contra a escravidão. Observou-se nessas entrevistas, a relação das mulheres na constituição da família, no trabalho, nas crenças e nas vivências cotidianas. Empregou-se a técnica análise de conteúdo (BARDIN, 1977; FRANCO, 2007) para organizar e categorizar os dados.

\section{Resultados e discussões}

Discute-se o conceito de cultura e de educação como processos sociais devido a sua importância no contexto da pesquisa, por ser temática transversal ao objeto estudado. Constatou-se que a nova geração de mulheres quilombolas de Araçatiba difere em vários aspectos das mais velhas, a começar pelo grau de instrução e conclusão do ensino médio, além da inserção ao mercado de trabalho fora da comunidade.

A educação se presentifica em contextos sociais e é vital à cultura, pois existe "[...] na consciência do ser humano, na ideologia de grupos sociais, e sua missão é transformar os sujeitos e as coisas em algo melhor. [...] na escola, na igreja, no trabalho ou na rua, a educação envolve todos para aprender ou para ensinar" (MANTOVANI, 2018, p. 49). Adiciona-se a isso conforme a compreensão de Gomes (2002):

Essas concepções e essas práticas pedagógicas, repletas de valores e representações negativas sobre o negro resultam, muitas vezes, na introjeção do fracasso e na exteriorização do mesmo pelos alunos e alunas, expresso numa relação de animosidade com a escola e com o corpo docente. Diante de uma estrutura e de práticas excludentes não é de se estranhar que muitos alunos e alunas negras introjetem o racismo e o preconceito racial (GOMES, 2002, p. 41-42). 
Considera-se que tanto a educação quanto a cultura são processos sociais de longa duração. Elias (2008) entende que a relação entre o indivíduo e as estruturas sociais deve ser analisada e concebida como um processo. Nessa perspectiva, pode-se considerar que as "estruturas sociais" (sistema social) e "indivíduo" (ego) são aspectos diferentes, mas inseparáveis, porque são as teias de interdependências humanas que formam as configurações sociais. Para Elias (2008):

[...] pessoas constituem teias de interdependência ou configurações de muitos tipos, tais como famílias, escolas, cidades, estratos sociais ou estados. Cada uma dessas pessoas constitui um ego ou uma pessoa, como muitas vezes se diz numa linguagem reificante. Entre essas pessoas colocamo-nos nós próprios (ELIAS, 2008, p. 15-16).

Em outros termos, é necessário repensar sobre a linguagem na contribuição de Munanga (2005, p. 9-10), como sendo:

[...] uma das manifestações mais próprias de uma cultura. Longe de ser apenas um veículo de comunicação objetiva, ela dá testemunho das experiências acumuladas por um povo, de sua memória coletiva, seus valores. A linguagem não é só denotação, é também conotação. Nos meandros das palavras, das formas usuais de expressão, até mesmo nas figuras de linguagem, frequentemente alojam-se, insidiosos, o preconceito e a atitude discriminatória. Há palavras que fazem sofrer, porque se transformaram em códigos do ódio e da intolerância.

Em sua teoria, Elias estuda o processo civilizador e concebe que há interdependência entre as áreas de saberes e interdependência entre os indivíduos, rompendo assim com a divisão entre indivíduo e sociedade, na qual profissionais, ao fragmentarem conhecimentos, perdem aspectos importantes tanto da sociogênese como da psicogênese. "O conceito de configuração chama a atenção para a interdependência das pessoas" (ELIAS, 2008, p. 144). Daí a importância de se valorizar a interface e entre as políticas públicas que, nesta pesquisa, devem ser consideradas como a intersetoriedade entre os processos sociais de educação formal/informal e a cultura, atravessadas por tensões, mediações, angústias, autocoerções e conflitos. Portanto, interdependência não significa harmonia.

Ao conjecturar sobre a cultura do senso comum, é necessário afirmar o valor da escrita como ferramenta do resgate da memória social no campo educacional e possibilitar que as vivências dos indivíduos no decorrer da vida, nos aspectos presentes de falas e experiências de gerações anteriores, ocorram em períodos lineares ou passados, podendo ser preservadas, junto com as memórias e tradições antigas. Tem, de antemão, o uso da oralidade como transmissão das tradições, comumente de cunho dos saberes religioso, mítico e genealógico, possuindo valor primário que antecede à escrita. A cultura para Elias (1994b) é entendida como: 
[...] a capacidade para produzir conhecimento baseado na fantasia é um dom humano tão fundamental e distintivo quanto à capacidade para produzir conhecimento e pensamento congruentes com a realidade ou, por outras palavras, racionais. A incapacidade de descobrir nos modelos teóricos da humanidade um lugar para as fantasias é um dos factores responsáveis pela incapacidade de articular as teorias da cultura e, assim, também da religião com as teorias de outros aspectos dos seres humanos e das suas diversas manifestações (ELIAS, 1994b, p.78).

Ao ensinar a história da África hoje no Brasil, é combater o racismo estrutural violento, na sua face mais explícita, como o racismo religioso, a intolerância e o ódio que repercutem em diversos estratos sociais.

Corrobora com essa informação Munanga (2004) ao destacar que a discriminação racial: "[...] precisa ser urgentemente enfrentada. Nós, negros, também temos problemas de alienação de nossa personalidade. Muitas vezes trabalhamos o problema na ponta do iceberg que é visível. Mas a base desse iceberg deixa de ser trabalhada" (MUNANGA, 2004, p. 54).

A Lei 10.639/2003 coaduna com a garantia fundamental de igualdade para povos tradicionais, afrodescendentes e de maneira mais ampla à sociedade brasileira, enquanto sujeitos de direitos. Há urgência em se valorizar a preservação da cultura negra que se expressa nas Diretrizes Curriculares Nacionais para o estudo da Educação das relações étnico-raciais e para o ensino da História e Cultura Afro-brasileira em todas as disciplinas, não apenas exclusivo à História. Vale ressaltar que a lei 10.639/2003 "Altera a Lei no 9.394, de 20 de dezembro de 1996, que estabelece as diretrizes e bases da educação nacional, para incluir no currículo oficial da Rede de Ensino a obrigatoriedade da temática "História e Cultura Afro-Brasileira", e dá outras providências" (BRASIL, 1996).

Por conseguinte a Lei no 10.639, de 9 de janeiro de 2003 foi modificada pela Lei no 11.645, de 10 de março de 2008 (BRASIL, 2008), para estender a temática para a história e a cultura indígena, como política pública da diversidade cultural e do enfrentamento racial na educação, mediante a formação e a capacitação docente que visem proporcionar a inclusão de novas práticas pedagógicas e curriculares para a educação das relações étnico-raciais potencializadas nas:

[...] instituições escolares para o desenvolvimento e estratégias que possibilitem a valorização da diversidade humana, de uma educação equânime, principalmente pela Lei elencar implicitamente que os currículos escolares hegemônicos precisam ser repensados e reconstruídos, para que seja trabalhada na escola a Cultura Afro-Brasileira, Africana e a Indígena (MENEZES, 2016, p. 92-93).

Essas Leis resultam de diversas lutas e demandas de estudiosos do tema: educadores, intelectuais, militantes do movimento negro, legisladores, 
movimentos sociais, religiosos e artistas com criticidade e resistência tentam visibilizar a urgência do debate sobre o tema História da África. E um dos maiores desafios para a sua implementação e difusão é trabalhar com a pluralidade de muitas Áfricas, de um grande continente, em vários países com línguas, culturas e povos diferentes.

Reis (2009) argumenta que, para a compreensão da identidade do ser humano, é necessário primeiro entender as relações sociais do meio em que vive. O comportamento individual irá refletir a forma como funciona a sociedade, o poder do controle e da influência sobre cada pessoa, conforme cita Elias (2008, p. 139), "O sentido que cada um tem de sua identidade está estreitamente relacionado com as relações de nós e de eles no nosso próprio grupo e com a nossa posição dentro dessas unidades que designamos nós e eles". Entretanto, vale ressaltar que, mesmo nessas diferenças, há uma semelhança, principalmente após o desagrupamento social desses povos, sobretudo porque se percebiam em suas semelhanças culturais continentais, criando novas identidades como refúgio e resistência criando os quilombos.

Reis (2009) explica que, por meio da construção de sua identidade, os grupos que foram menosprezados historicamente lutam pela inclusão de políticas públicas e políticas de ações afirmativas para que possam ser reconhecidos e tenham acesso aos direitos que Ihes foram negados por séculos, em favor de reconhecimento de sua dignidade humana e representação social:

Diante do exposto, nosso entendimento é que o termo identidade corresponde a um conjunto de aspectos políticos e sociais, individuais e coletivos, assumido por uma pessoa. Cada um vai sendo identificado, de forma diferente, a partir do seu grupo de pertencimento e, desta forma, vai construindo e assumindo uma identidade e pertencimento neste grupo. Portanto, a identidade vai sendo construída e se adaptando aos grupos, aos lugares, aos costumes, às opções feitas por cada um (REIS, 2009, p. 5).

Existem muitas maneiras de encontrar essas Áfricas no Brasil, e toda essa complexidade se faz olhando para o continente, em especial, dialogando com intelectuais e educadores. Nas múltiplas identidades e realidades existem amplas regiões africanas de semelhanças em grupos e povos, em relações linguísticas e culturais que tornam os estudos possíveis com perspectivas comuns ao estudar grandes povos:

Contudo, são temáticas que estão relacionadas às diferenças sociais, a intolerância, o desrespeito mútuo, que não surgiram do nada, portanto tem uma história que, em geral tem suas raízes na intolerância referente as diferenças ou diversidade social, racial, étnica e cultural. Assim sendo tais desconstruções alienantes são possíveis por meio do incentivo ao exercício do debate, da reflexão, da ressignificação das fronteiras, do reconhecimento da identidade, da solidariedade e do respeito às diferenças individuais (PEREIRA, 2014, p. 56). 
Portanto, redescobrir essas Áfricas no Brasil, a partir da experiência nas diásporas, das redes em comum de celebração, culturas, religiosidades, todas essas formas de diálogo permitem o enriquecimento da valorização da cultura.

Pereira (2014) destaca a relação entre o projeto hegemônico de educação e cultura e as minorias étnico-raciais:

Tal negação é constituída por controle de poderes estabelecidos por uma classe social burguesa, que não permite que outros grupos sociais sejam reconhecidos verdadeiramente por meio do currículo escolar. Logo, tais culturas como as indígenas, africanas, afrobrasileiras são tratadas de forma pejorativa e sem nenhuma ressignificação histórica de seu tempo e espaço (PEREIRA, 2014, p. 56).

Dentro dessa premissa, reforça-se a importância da descolonização da educação e da cultura, para o reconhecimento da história a partir do protagonismo dos quilombolas, enquanto sujeitos de direito, no enredamento de narrativas de quem passou pelas auguras da opressão. Processo esse que ocorre por meio da "transmissão da cultura intra e intergeracional" e "tecendo afetos em comunidade" que serão abordados a seguir.

\subsection{A transmissão da cultura intra e intergeracional}

Fernandes e Zanelli (2006) apontam que a formação dos indivíduos na identidade organizacional acontece a partir do momento em que ele ingressa em um sistema sociocultural, buscando por uma finalidade semelhante, ao formar essa união com partilhas de crenças, hábitos, valores, que farão o contexto de grupo, predefinindo sua identidade cultural. Os autores afirmam que, através do compartilhamento e da exposição, a realidade das identidades é construída, comunicando-se com os outros membros, por meio da troca mútua das normas, valores, e outras criações, de modo organizacional. A partir do instante que essa identidade social é formada, tem-se a intenção da manutenção e da harmonia quanto ao que foi aprendido e socializado.

Neste sentido é importante apresentar o conceito de configuração em Elias, que segundo Costa (2017) compreende:

A formação dos indivíduos na sua relação com os objetos simbólicos, com a transmissão da cultura e com o aprendizado de um patrimônio simbólico social. $O$ indivíduo que não foi educado com símbolos de uma cultura, que não aprendeu uma língua ou que não inscreveu elementos sociais em seu processo de subjetivação não se desenvolve propriamente como um ser humano. Assim, devido à interdependência entre os indivíduos, mesmo em situações de desordem, caos, rompimentos ou desintegrações sociais, os indivíduos sempre acabam se agrupando em configurações específicas (COSTA, 2017, p. 43). 
Para Fernandes e Zanelli (2006), a cultura cumpre o papel organizacional no processo de formação da identidade de cada indivíduo, como um dos maiores fatores da sobrevivência do ser humano. É a construção da sua identidade um entendimento de totalidade e pertencimento ao grupo de que faz parte, diante das diversas representações sociais que ele exerce. Sendo assim, se modula, transforma e iguala, de acordo com os grupos sociais a que ele pertence, fazendo a realidade mutável, por vezes até mesmo contraditória.

O fato de as identidades sociais não serem fixas, uma vez que estão sempre construindo-se e reconstruindo-se no processo social de construção do significado. Em oposição a uma visão tradicional, que compreende a identidade social de um indivíduo como fixa e contínua, como algo que lhe pertence de modo quase permanente, uma corrente significativa de autores tem procurado desenvolver um conceito de identidade como algo fluido, multidimensional, dependente do contexto sociocultural das situações nas quais os indivíduos se veem envolvidos, e como algo que possui forte componente relacional (FERNANDES; ZANELLI, 2006, p. 61).

As mulheres quilombolas, como mantenedoras do legado cultural, carregam as tradições religiosas e culturais nos laços familiares e nos saberes tradicionais, formando uma rede de solidariedade.

As mulheres são verdadeiras mestras dos saberes transmitidos às futuras gerações através da oralidade, garantindo, assim, a continuidade dos conhecimentos ancestrais presentes na comunidade. A oralidade é a principal forma de transmissão dos ensinamentos. Desde criança, o(a)s filho(a)s aprende $(m)$ com os mais velhos as práticas de trabalho, as regras de comportamento e convivência - como o respeito aos mais velhos (SILVA, 2014, p. $56)$.

De acordo com Oliveira (2007), tradições, saberes e costumes são passados nos processos intrageracionais, construídos e mantidos como preservação da vida em comunidade e todo o seu modo de estrutura organizacional. No Brasil, em grande parte dos quilombos os saberes populares são dominados por conhecimentos a respeito religiosos, como rezas curadoras, ervas medicinais, culinária, vestimentas e adornos corporais, entre outros. Constitui uma riqueza de saber, desde o remédio natural até processo do parto.

Verdadeiros celeiros da tradição africano-brasileira, os quilombos têm sua identidade preservada pela perpetuação de seus costumes e de suas tradições, repassados, ao longo dos séculos, pelos mais velhos aos mais novos. Por meio das histórias e de práticas milenares, repassam a memória de um povo. A utilização de ervas medicinais para a manutenção da saúde e a prática das parteiras tradicionais estão entre alguns saberes preservados (MOURA, 2007, p. 7). 
Oliveira (2007) evidencia que as comunidades quilombolas têm como patrimônio imaterial a expectativa depositada nos conhecimentos medicinais nos processos das doenças, como refúgio em suas necessidades pontuais de tratamento e de nascimento, de modo ainda mais enfático nas mulheres "parteiras" e "remedieiras", pois elas simbolizam a continuidade dos ensinamentos e atuam na linha de frente nos cuidados mais presentes no meio familiar. Desse modo, através das relações sociais as lideranças femininas nascem de modo naturalizado.

A estratégia organizacional das comunidades quilombolas assinala a importância da valorização dos saberes tradicionais e da perpetuação dos conhecimentos, no legado da saúde, da religião e dos costumes, que englobam - legado cultural transmitido das gerações mais velhas para as mais novas. Salienta-se o quanto a educação é importante na preservação cultural, com todos os saberes tradicionais.

O fortalecimento da cultura quilombola é concomitante aos espaços que perpetuam a frutificação dos saberes, com a garantia do direito ao acesso à terra, dando abertura e debate no currículo escolar e nas correlações culturais (OLIVEIRA, 2007). Para compreender o processo, insta destacar a contribuição de Gomes (2002) acerca da identidade negra:

É nesse sentido que entendo a identidade negra como uma construção social, histórica e cultural repleta de densidade, de conflitos e de diálogos. Ela implica a construção do olhar de um grupo étnico/racial ou de sujeitos que pertencem a um mesmo grupo étnico/ racial, sobre si mesmos, a partir da relação com o outro. Um olhar que, quando confrontado com o do outro, volta-se sobre si mesmo, pois só o outro interpela a nossa própria identidade. Enquanto dois processos densos, construídos pelos sujeitos sociais no decorrer da história, nas relações sociais e culturais, a educação e a identidade negra estão imersas na articulação entre o individual e o social, entre o passado e o presente, e são incorporadas, ao mesmo tempo em que incorporam, à dinâmica do particular e do universal (GOMES, 2002, p. 39).

Falar sobre educação popular, para Brandão e Vitória (2018), é refletir sobre todo o ordenamento da educação, sob até mesmo a ótica de quem tem o entendimento mais atraído por mudança e transformação da educação popular, que não é fixa somente no ambiente escolar e resiste às variações de mudanças na contramão.

A educação popular é mais que um modelo de educação que trabalha simultaneamente com a educação pedagógica tradicional. É um projeto constituído de um conjunto de ideias e transformações sobre como educar de forma popular, com uma dinâmica própria da comunidade. 
É preciso recuar longe, memórias de um passado remoto, para conhecermos como o saber terá emergido à vida e, circulando entre tipos de pessoas, terá diferenciado uma região de si mesmo como educação. Como isto terá se passado muito antes de seres, pouco a pouco, haverem dominado a escrita, é evidente que não ficaram marcas e tudo o que os investigadores do assunto encontram são sinais efêmeros, de que constroem suposições (BRANDÃO; VITÓRIA, 2018, p. 3).

Conforme o site da Prefeitura de Viana (2017), o Congo é "[...] ferramenta de ensino em escola de Araçatiba", o que une a educação informal que é dada pelo meio familiar por meio da transmissão intra e intergeracional dos povos tradicionais, agregando-a a "educação formal", como lembrado pela diretora Andréa Correa:

Tambor, casaca, cuíca e apito no lugar de quadro e giz. É assim, por instrumentos tradicionais do Congo, que os alunos da Escola Municipal de Ensino Fundamental (EMEF) Araçatiba aprendem sobre escrita, leitura e as regras gramaticais. Segundo a diretora da instituição, Andréa Correa, a iniciativa de usar uma das mais tradicionais expressões culturais de Araçatiba para transmitir o conteúdo partiu dos próprios estudantes (VIANA, 2018).

Mesmo com o território da Comunidade Quilombola de Araçatiba sendo perdido e parte do modo de vida tradicional, as manifestações culturais resistem. Não obstante, a história da comunidade é transmitida de maneira oral por seus moradores longevos, os bens do patrimônio cultural imaterial são salvaguardados como a congada por meio da banda de congo Mãe Petronílha e são repassados às novas gerações por meio da banda mirim, da capoeira e dos rituais africanos, que em dia de festa, dividem a liturgia católica (NEEPES/ENSP/FIOCRUZ, 2009). Adiciona-se ao debate o entendimento de Gomes (2002):

Existem diferentes e diversas formas e modelos de educação e a escola não é o lugar privilegiado onde ela acontece e nem o professor e a professora são os únicos responsáveis pela sua prática. Contudo, apesar de considerar essa dimensão mais ampla e mais geral do processo educativo, este artigo privilegiará a educação que acontece no interior da instituição escolar. A escola é vista, aqui, como um espaço em que aprendemos e compartilhamos não só conteúdos e saberes escolares mas, também, valores, crenças e hábitos, assim como preconceitos raciais, de gênero, de classe e de idade (GOMES, 2002, p. 39).

Segundo Menezes (2016, p. 104), para que a escola desempenhe sua função formadora, os "[...] currículos hegemônicos de controle precisam ser modificados, reconhecendo a educação multicultural e antirracista" como a necessidade de valorizar a "[...] formação continuada e o reconhecimento da dívida histórica do Estado com os negros [...], podendo proporcionar caminhos 
na construção de uma sociedade sem preconceitos, mais justa e que respeite e valorize as diferenças".

Isso ratifica a narrativa da entrevistada $A D E L I N A$, que informou sobre a transmissão geracional ao seu filho, desde a infância:

A minha família é tudo misturado com a cultura. O meu pai, a minha bisavó e tataravó, a mãe Petronilha, que foi quem fundou o congo. Aí, foi passando para a minha avó, minha avó passou para o meu pai. Agora fica na casa do meu avô os congos. Agora o meu filho bate o congo. E eu levo ele para apresentar nos lugares. Então foi passado para a minha família (ADELINA).

Destaca-se a importância dos ritos religiosos e comemorativos, que contribuem para manutenção e memória do legado e das festividades culturais expressas através da Banda de Congo na sua contribuição de continuidade às gerações mais novas, como também trazendo vitalidade às gerações mais antigas, no seio da preservação de seus ancestrais:

Quando se constata a riqueza criativa das vivências dos moradores das comunidades remanescentes de quilombos, principalmente dos mais velhos, no que diz respeito ao uso das ervas medicinais, no modo de trabalhar a terra, de tirar dela seu sustento, nas linguagens gestuais, na música, nas festas, no modo de se divertir, de cantar, dançar e rezar vê-se a importância de ter acesso a esse conhecimento. É esse conhecimento que constitui o contexto em que se tecem as teias de significados que recriam incessantemente sua cultura e sua identidade contrastiva, isto é, a afirmação da diferença. Nas práticas dos moradores das comunidades, há um forte apelo ao reconhecimento dessa identidade (GOMES, 2007, p. 23).

Nas Bandas de Congo, a religiosidade é manifestada por meio de entoadas e cantigas, festas, santos de devoção e outros elementos simbólicos. Nesse sentido, é importante e pertinente destacar a contribuição de Santos (2016, p. 225) quando relata que nas "[...] expressões culturais afro-brasileiras, religiosidade está inserida em todas as dimensões da vida (arte, vida social, religião, festas, dentre outras), que são incontestadamente ligadas".

As Bandas de Congo se configuram como manifestação cultural que incorpora o ritual religioso ao ciclo social e, portanto, fazem parte da vida dos remanescentes quilombolas em Araçatiba. Os saberes que são passados de modo permanente na transmissão intrageracional provocam reflexões, a partir das mudanças naturais ocorridas nas comunidades tradicionais, causando adequação a cada uma dessas mudanças. No entanto, é nos rituais, tradições, festas que os valores alicerçados são reiterados ou reavaliados, provocando novas construções, mesmo que invisíveis, mas com aplicação nas tradições e resistência e convívio como comunidade. Apontam-se novos espaços, conhecimentos, expõem-se às novas gerações os valores dos seus antepassados e as novas possibilidades (GOMES, 2007), como expõe Adelina: "Eu incentivo 
ele, eu falo assim, olha fulano... A sua vó, sua tataravó ela fundou o congo, ai passou para o seu pai, a sua vó... Agora a gente faz parte também da banda de congo [...]. A gente é afrodescendente sim, a gente é quilombola sim, o congo é importante pra gente, e eu incentivo ele...". Nesse sentido, Vieira, Vieira e Silva (2019) descrevem que:

Mais do que uma característica cultural, o Congo pode ser considerado como um elemento impactante na formação históricocultural, resultando no modo de pensar e agir da sociedade capixaba, através de costumes, valores, entoadas (músicas) e festejos, que devem ser preservados para que nunca se perca a singularidade desta manifestação popular. Partindo desse princípio percebe-se que se trata de uma herança acumulada ao longo dos anos e que deve ser preservada, e como cultura popular associase a algo criado por um determinado grupo de pessoas que possuem participação ativa nessa criação. (VIEIRA; VIEIRA; SILVA, 2019, p. 106, grifo dos autores).

Moura (2007) reconhece que é na vivência em comunidade que a população tradicional encontra semelhança entre si, bem como o autorreconhecimento, o que a fortifica nos "embates" por titulação e é sintoma de sua resistência. Para exercer o papel da liderança em sua função política na transformação local, essa população deve trabalhar em projetos culturais e sociais.

O maior legado que eu acho é a devoção a Nossa Senhora da Ajuda. Vai passando devoção, já encontramos na família. E até hoje temos muito amor a nossa Igreja Católica e a Nossa Senhora da Ajuda que é a nossa padroeira. [...] A maior tradição é a igreja em primeiro lugar e depois a tradição da Banda de Congo. E era a diversão deles e nós conservamos até hoje. A diversão dos negros (DANDARA DOS PALMARES).

Mascaranhas e Oliveira (2007) apontam sobre a raiz da tradição, de como ela é marcada pelos antepassados de África e de sua diáspora, e de todos os saberes, riquezas, culturas e subjetividades de um povo. Esses saberes são refletidos em materialidade nos ritos, nas vivências e na sua perpetuação por via da oralidade na sua transmissão. Desde antiguidade, os povos tinham uma organização política, cultural, religiosa, toda fundamentada em suas tradições. Isso foi transmitido pelos mais velhos às gerações mais novas, constituindo o legado deixado de toda história do seu povo, com sua mitologia e sua cultura. Os conhecimentos das famílias se constituíram das diversas manifestações culturais partilhadas em músicas, artesanatos, culinária, fazeres do cotidiano e outros, como salienta Anastácia: "Pai, eu não conheci não, conheci a minha mãe. Ela me ensinou a cozinhar, lavar a roupa, fazer assim coisa de comida, sabão, bolo. Eu plantava, fazia farinha. De noite eu descascava o melado, aipim. Tudo a gente fazia, antigamente nós não comprávamos". Assim, ressalta-se que: 
Não é fácil construir uma identidade negra positiva convivendo e vivendo num imaginário pedagógico que olha, vê e trata os negros e sua cultura de maneira desigual. Muitas vezes os alunos e as alunas negras são vistos como "excluídos", como alguém que, devido ao seu meio sociocultural e ao seu pertencimento étnico/racial, já carrega "dificuldade" de aprendizagem e uma tendência a "desvios" de comportamento, como rebeldia, indisciplina, agressividade e violência (GOMES, 2002, p. 41-42).

A educação numa perspectiva inclusiva tem o papel de promover o respeito, na qual os afetos fortalecem vínculos de pertencimento e de identidades, com a percepção da diversidade humana.

\subsection{Tecendo afetos em comunidade}

Como forma de resistência, enfatiza a importância dos espaços organizacionais como espaços de lutas, com as tradições vigentes culturais e as conquistas das mulheres quilombolas:

As formas particulares com que cada indivíduo elabora uma ideia, assume um comportamento ou toma suas decisões são construídas e difundidas pelas forças reticulares exercidas no âmbito das relações humanas destinadas ao controle dos afetos (XAVIER, 2020, p. 212).

A entrevistada ADELINA aponta que maior legado cultural da comunidade mantido sem interrupção, é a Banda de Congo: "Se eu não me engano, o maior legado que não saiu assim, que está desde o começo, eu acho que é o Congo. É antigo esse Congo..."

Torna-se relevante destacar que o site da Prefeitura de Viana (2018) cita a importância e a presença feminina na cultura local: "A Banda de Congo Mãe Petronilha também marca presença na história de Araçatiba. O nome é em homenagem a Petronilha Maria da Conceição, antiga guardiã dos instrumentos da banda, organizadora da Festa de São Benedito e parteira da região" (VIANA, 2018, s/p.).

A Missa Afro e a Cooperativa CosturArte eram os antigos espaços organizacionais que havia dentro da Comunidade, com o envolvimento das mulheres à frente. No entanto, com o deslocamento da liderança, em especial, da Cooperativa, ficou em modo inativo. É importante frisar a relevância que esses espaços provocam para o crescimento e a unidade, não somente das mulheres e para a comunidade, assim como a ausência dos espaços podem provocar o enfraquecimento.

A entrevistada Acotirene revela a descoberta de uma identidade cultural que foi debatida em um desses espaços coletivos de reuniões: "Eu lembro quando nós fizemos uma reunião, foi lá em cima na igreja. Nós fizemos tipo uma roda, e cada uma falou um pouco sobre o que pensava; o que era aqui; o que a 
gente gostava de comer, esses negócios. Aí discutimos muito sobre isso, sobre fazer 'Soteco de Banana com moqueca de peixe'" (ACOTIRENE).

Cabe informar que a gestão pública municipal realizou um programa de resgate das tradições culinárias da comunidade, com oficinas onde as mulheres compartilharam receitas tradicionais que estavam esquecidas e aprenderam a culinária de suas antepassadas (NEEPES/ENSP/FIOCRUZ, 2009).

Várias mulheres entrevistadas relataram ter a mesma preferência ao perceberem que todas preparavam alimentos com receitas comuns, sendo um traço cultural da comunidade. Trata-se de "[...] posições básicas que situam as relações das diversas configurações, seja daquele que fala "por si" ou "pelo grupo" ao qual pertence. Isso indica que o indivíduo singular se refere a uma pessoa em relações de interdependência e a sociedade ao conjunto de pessoas em relações de interdependência" (COSTA, 2017, p. 47).

Angola e Reis (2016) discutem a população tradicional, reconhecem o sinônimo de resistência que as mulheres quilombolas carregam, cumprindo sua função como coluna fundamental na organização social da comunidade. Ainda nos dias atuais, o que mais ressoa é a importância do papel de continuidade das mulheres na parte organizacional, no campo político, econômico e social, para a sua sobrevivência política e afirmativa na legitimidade como povos tradicionais, em todo planejamento e execução organizacional. É importante na estruturação e desenvolvimento de luta.

Essa forma de organização, luta e resistência foi construída por mulheres e homens. No entanto, também tivemos parte dessa história negada. Não são suficientes os registros que temos hoje sobre os quilombos para entender a complexidade de seu processo de organização, assim como as especificidades dos diversos territórios espalhados por todo o País. Além de Zumbi dos Palmares, em cuja homenagem se comemora, no dia 20 de novembro, o Dia da Consciência Negra, temos lideranças femininas dessa resistência, como Aqualtune e Dandara, ambas também de Palmares. A primeira foi princesa do Congo no século XIII, guerreira africana que quando escravizada lutou contra o regime. A segunda é comumente referida como companheira de Zumbi, mas também exerceu papel de protagonismo na luta quilombola (ANGOLA; REIS, 2016, p. 1).

Brito e outros (2004) citam as atribuições dos espaços organizacionais ocupados por homens e mulheres no trabalho da articulação das negociações e da luta, dentro do movimento, e no trabalho sobre o foco dos interesses em questão. Essas relações são evidenciadas como ferramenta nas práticas das relações sociais.

Isso posto, o papel das mulheres na comunidade é fundamental, desde o passado, com as guerrilheiras, até os dias atuais, com as quilombolas. Na luta por visibilidade, a prevalência é das mulheres e o comando também é delas. No histórico do sustento da comunidade, seja trabalhando fora, seja na educação 
dos filhos em casa, elas estão presentes. Dessa forma, a entrevistada Aqualtune relata a sua maior conquista:

O que eu avancei foi a educação dos meus filhos. Graças a Deus todos trabalham, não têm vício. Graças a Deus soube criar meus filhos, minhas filhas... Dei estudo para eles. Todos eles terminaram os estudos. A minha vitória sendo quilombola, são essas. Porque naquela época uma mãe não deixava os filhos estudar. (AQUALTUNE).

É possível ressignificar a identidade do/a negro/a, a partir do momento que é possível o reconhecimento da reparação histórica, abrindo espaços para a educação, a cultura, as tradições, os valores e os costumes de um povo, que por muito tempo foram mantidos invisíveis, com o controle das emoções, quando Ihe era imposto um "processo civilizador", conforme Elias (1994a) citado por Reis (2009).

De acordo com a teoria elisiana, identidade é uma concepção construída em redes comunitárias de estruturas afetivas, e que só podem ter sua concepção de vida social quando houver liberdade para todos os indivíduos, que possam sentir-se à vontade e desfrutar da companhia juntos. Essa liberdade necessita funcionar na co-dependência das estruturas sociais, não somete para uma privilegiada camada social.

\section{Considerações finais}

É necessário que se apresente o conhecimento para a sociedade de uma África contemporânea, com temas desvinculados à escravidão, utilizando outras representações do continente em nossa contextualização brasileira. E apresentar esse ensino com desafios e também novas possibilidades. Como por exemplo, a cultura que é uma deles: danças, culinária, músicas, pinturas e todas as riquezas trazidas do continente.

Neste processo, evidencia-se a construção e a importância da vida das mulheres negras, máxime as mulheres quilombolas, que são vozes de respostas às desigualdades raciais e de gênero que vivem. Essas mulheres e sua sobrevivência representam um ato político para a luta por direitos, implementações, voz e visibilidade no seu território e na sociedade brasileira. A ausência de conhecimento e pertencimento da identidade negra contribui para sérios prejuízos emocionais e sociais, que se amplificam na coletividade.

A teoria sociológica de Norbert Elias potencializou as discussões em especial, pelos conceitos que foram aqui abordados. É necessário desenvolver estudos com aprofundamento para essa população e sua mobilização social, mas, sobretudo, maior efetividade jurídica das políticas públicas já existentes. Os autores, que produzem saberes a partir da perspectiva da epistemologia negra, contribuíram ao discutir a cultura quilombola para se repensar sobre as amarras que estão no nosso cotidiano, nas relações sociais e nos currículos escolares para se lutar contra o racismo estrutural. 
Soma-se a metodologia da descolonização que prima em potencializar a desconstrução dos modos de discutir e vivenciar valores da cultura e poder eurocêntricos, e por este modo é urgente à perspectiva da epistemologia negra, que sobremaneira centra nessas contradições que, por anos a fio, foi massificada à população negra, e que a todo o momento necessita de ser contestada e desconstruída.

Falta valorização identitária para possibilitar a compreensão e a complexidade da identidade, anulando a importância de quem possui legitimidade como construtor de um legado cultural como agente de transformação, dentro da História, com uso da epistemologia negra.

Torna-se relevante destacar que esta pesquisa é um recorte da realidade social expressa na comunidade quilombola de Araçatiba, portanto há limites que fomentam novas pesquisas, sobretudo para a discussão dos processos de descolonização nos currículos escolares, com a perspectiva epistemológica negra, para o não distanciamento de seus moradores da cultura genuína local e que, por conseguinte, a não negação de práticas, saberes e fazeres da cultura quilombola.

\section{REFERÊNCIAS}

ANGOLA, Catarina de; REIS, Mariana. Quilombo como organização, luta e resistência das mulheres. Brasil de Fato, Recife, 28 nov. 2016. Disponível em: https://www.brasildefatope.com.br/2016/11/28/quilombo-comoorganizacao-luta-e-resistencia-das-mulheres. Acesso em: 17 mar. 2019.

BARDIN, Laurence. Análise de conteúdo. Lisboa: Edições 70, 1977.

BERNARDINO-COSTA, Joaze; GROSFGUEL, Ramón. Decolonialidade e perspectiva negra. Revista Sociedade e Estado - Volume 31 Número 1 Janeiro/Abril, p. 15-24, 2016.

BRANDÃO, Carlos Rodrigues; VITÓRIA, Maurício Cesar. Cultura popular e educação popular: expressões da proposta freireana para um sistema de educação. Educar em Revista, Curitiba, n. 61, p. 89-106, jul./set. 2016. Disponível em:

https://aedmoodle.ufpa.br/pluginfile.php/183720/mod_resource/content/1/O $\% 20$ que $\% 20 \%$ c3\%a9\%20educa\%c3\%a7\%c3\%a3o\%20popular.pdf. Acesso em: 21 fev. 2018.

BRASIL. Contribuições para a Implementação da Lei 10639/2003: proposta de plano nacional de implementação das diretrizes curriculares nacionais da educação das relações étnico-raciais e para o ensino de história e cultura afrobrasileira e africana: Lei 10639/2003. Brasília, DF, 2008. Disponível em: http://www.portal.mec.gov.br. Acesso em: 15 mar. 2021. 
BRASIL. Lei no 11.645 de 10 de março de 2008. Disponível em: http://www.planalto.gov.br/ccivil_03/_Ato2007-2010/2008/Lei/L11645.htm

BRITO, Maria José Menezes; MELO, Marlene Catarina de Oliveira Lopes; CAPPELLE, Mônica Carvalho Alves.; BRITO, Mozar José de. Uma análise da dinâmica do poder e das relações de gênero no espaço organizacional. RAE PUBLICAÇõES [online], v. 3, n. 2, jul./dez. 2004. Disponível em: https://rae.fgv.br/rae-eletronica/vol3-num2-2004/analise-dinamica-poderrelacoes-genero-no-espaco-organizacional. Acesso em: 17 mar. 2018.

COSTA, André Oliveira. Norbert Elias e a configuração: um conceito interdisciplinar. Configurações [online]. Disponibilizado em 30 jun. 2017. Disponível em:

https://www.researchgate.net/publication/318117747_Norbert_Elias_e_a_conf iguracao_um_conceito_interdisciplinar. Acesso em: 8 abr. 2019.

ELIAS, Norbert. O processo civilizador: uma história dos costumes. Rio de Janeiro: Jorge Zahar, 1994a. v. 1.

ELIAS, Norbert. Teoria simbólica. Oeiras: Celta Editora. 1994b.

ELIAS, Norbert. Sobre o tempo. Rio de Janeiro: Jorge Zahar Ed., 1998.

ELIAS, Norbert. Escritos e Ensaios 1: Estado, processo e opinião pública. Organização de Frederico Neiburg e Leopoldo Waizbort. Rio de Janeiro: Jorge Zahar, 2006.

ELIAS, Norbert. Introdução à Sociologia. São Paulo: Edições 70, 2008.

FERNANDES, Karina Ribeiro; ZANELLI, José Carlos. O processo de construção e reconstrução das identidades dos indivíduos nas organizações. RAC, v. 10, n. 1, p. 55-72, jan./mar. 95 2006. Disponível em:

https://www.scielo.br/pdf/rac/v10n1/a04.pdf. Acesso em: 17 maio 2018.

FRANCO, Maria Laura Puglisi Barbosa. Análise do conteúdo. 2. ed. Brasília: Liber Livro, 2007.

GOMES, Nilma Lino. Educação e Identidade Negra. Aletria: Revista de Estudo de Literatura. UFMG, Belo Horizonte. V. 9. 2002. Disponível em:

xhttp://www.periodicos.letras.ufmg.br/index.php/aletria/article/view/1296/139 2

Acesso em: 18 maio 2021.

GOMES, Nilma Lino. O Movimento Negro e a intelectualidade negra descolonizando os currículos. In: BERNARDINO-COSTA, Joaze.; MALDONADOTORRES, Nelson; GROSGOGUEL, Ramón (Orgs.). Decolonialidade e 
pensamento afrodiaspórico. Belo Horizonte: Autêntica Editora, 2018, p. 223-246 (Coleção Cultura Negra e Identidades).

GOMES, Verônica. Organização social e festas como veículos de educação não formal. In BRASIL. Ministério da Educação. Educação quilombola. Salto para o futuro. Boletim 10, Brasília, jun. 2007, p. 22-26. Disponível em: https://www.geledes.org.br/wp-content/uploads/2017/03/Educacaoquilombola.pdf. Acesso em: 17 maio 2018.

INSTITUTO BRASILEIRO DE ANÁLISES SOCIAIS E ECONÔMICAS; FURNAS CENTRAIS ELÉTRICAS SA; COMITÊ DE ENTIDADES NO COMBATE À FOME E PELA VIDA. Diagnóstico Social Araçatiba. Rio de Janeiro: IBASE/FURNAS; Vitória: COEP, 2006.

MASCARENHAS, M. D. M. DA. S.; OLIVEIRA, S. DA. S. Narrativas, tradições orais e suas manifestações nos Territórios Quilombolas África e Laranjituba, Moju PA: a narrativa do emu - a bebida sagrada. In: SIMPÓSIO NACIONAL DE HISTÓRIA, 29., 2017, Brasília. Anais eletrônicos... Disponível em: https://www.snh2017.anpuh.org/resources/anais/54/1502475660_ARQUIVO_ ARTI GO_COMPLETO_XXIX_SNH.pdf. Acesso em: 17 maio 2018.

MANTOVANI, Ludimila Nunes. A universidade pública e a democratização da cultura: o caso do auxílio cidadania cultural. 2018. 120 fl. Dissertação (Mestrado em Políticas Públicas 97 e Desenvolvimento Local) - Programa de Pós-Graduação em Políticas Públicas e Desenvolvimento Local, Escola Superior de Ciências da Santa Casa de Misericórdia de Vitória, Vitória, 2018.

MARTINS, Mirian Teresa de Sá Leitão Martins. A arte de trazer a vida pelas mãos. In ALVES, Míriam Cristiane; ALVES, Alcione Correa. (Orgs).

Epistemologias e metodologias negras, descoloniais e antirracistas. Editora Redeunida: Porto Alegre, 2020, p. 135-143. Disponível em: http://editora.redeunida.org.br/wp-content/uploads/2018/11/LivroEpistemologias-e-Metodologias-Negras-Descolonias-e-Antirracistas-1.pdf. Acesso em: 17 maio 2021.

MENEZES, Jussara Bezerra de. A lei 10.639/2003: política pública da diversidade cultural e enfrentamento do preconceito racial. 2016. $117 \mathrm{f}$. Dissertação (Mestrado em Políticas Públicas e Desenvolvimento Local) Programa de Pós-Graduação em Políticas Públicas e Desenvolvimento Local, Escola Superior de Ciências da Santa Casa de Misericórdia de Vitória, Vitória, 2016.

MOURA, Gloria. Quilombo: conceito. In BRASIL. Ministério da Educação.

Educação quilombola. Salto para o futuro. Boletim 10, Brasília, jun. 2007, p. 9-14. Disponível em: https://www.geledes.org.br/wpcontent/uploads/2017/03/Educacao-quilombola.pdf. Acesso em: 17 maio 2018. 
MUNANGA, Kabengele. A Difícil tarefa de definir quem é negro no Brasil. Entrevista de Kabengele Munanga. Estudos Avançados. 18 (50), 2004. Disponível em: https://www.scielo.br/pdf/ea/v18n50/a05v1850.pdf. Acesso em: 18 maio 2021.

MUNANGA, Kabengele. Superando o Racismo na Escola. Brasília: Ministério da Educação, Secretaria de Educação Continuada, Alfabetização e Diversidade, 2005.

\section{NEEPES/ENSP/FIOCRUZ, 2009. Mapas de Conflitos Envolvendo Injustiça}

Ambiental e Saúde no Brasil. Disponível em:

http://mapadeconflitos.ensp.fiocruz.br/conflito/es-com-sua-heranca-reduzidaa-um-quarto-quilombolas-de-aracatiba-buscam-reconhecimento-e-usamcultura-para-manter-vivas-as-tradicoes/. Acesso em: 20 maio 2021.

OLIVEIRA, Bárbara. Saberes tradicionais de saúde. In: BRASIL. Ministério da Educação. Educação quilombola. Salto para o futuro. Boletim 10, Brasília, jun. 2007. p. 15-21.

PEREIRA, Gilmar Ribeiro. A diversidade cultural e o currículo escolar: a ressignificação das relações étnico-raciais. PERSPEC. DIAL.: REV. EDUC. SOC., Naviraí, v.01, n.01, p. 55-63, jan-jun.2014. Disponível em: https://periodicos.ufms.br/index.php/persdia/article/view/17. Acesso em: 14 mar. 2021.

REIS, João José. (Resenha) Histórias de quilombolas: mocambos e comunidades de senzalas no Rio de Janeiro - século XIX (de Flávio dos Santos Gomes). História Social, (3), 197-200. Disponível em:

https://www.ifch.unicamp.br/ojs/index.php/rhs/article/view/92/87 Acesso em: 18 maio 2021.

REIS, Maria da Conceição dos Reis. O processo civilizador na construção da identidade negra. In: SIMPÓSIO INTERNACIONAL PROCESSO CIVILIZADOR, 12., 2009, Recife. Anais... Disponível em: http://www.uel.br/grupoestudo/processoscivilizadores/portugues/sitesanais/anais12/artigos/pdfs/comu nicacoes/C_Reis2.pdf. Acesso em: 21 fev. 2019.

SANTOS, José Elias Rosa dos. Congos e Bandas de Congos no Espírito Santo. In: OLIVEIRA, Osvaldo. Cleber Maciel: Negros no Espírito Santo. Martins de, 2. ed. Vitória: Arquivo Público do Estado do Espírito Santo, 2016.

SILVA, Egnaldo Rocha da. Mulher, negra e quilombola: sobrevivência e cotidiano na comunidade de Lagoa Santa, Ituberá-BA. GÊNERO, Niterói, v.15, n.1, p. 29-48, 2.sem.2014 Disponível em:

https://periodicos.uff.br/revistagenero. Acesso em: 8 de abr. 2019. 
VIANA (Prefeitura Municipal de Viana - ES). Congo é ferramenta de ensino em escola de Araçatiba. 23 ago. 2018. Disponível em:

http://www.viana.es.gov.br/site/publicacao/congo-como-ferramenta-deensino-em-escola-de-aracatiba. Acesso em: 8 abr. 2019.

VIEIRA, Ariele Azevedo da Silva; VIEIRA, Leonardo Barcelos; SILVA, Angela Maria Caulyt Santos da. Da casaca à resistência: o serviço social na promoção cultural do congo. In: MONTEIRO, S. A. de S. (Org.). A problemática da política social [recurso eletrônico], Ponta Grossa: Atena, 2019, p. 103-116.

VILANOVA, Mercedes. Pensar a subjetividade: estatísticas e fontes orais. In: FERREIRA, Marieta de Moraes (Org.). História oral e multidisciplinaridade. Rio de Janeiro: Diadorim, 1994. p. 45-73.

XAVIER, Cristiane Fernanda. Memórias do tornar-se professor - dinâmicas de individualização como chave de leitura dos processos envolvidos na escolha pelo magistério e na satisfação com a carreira docente. In VIEIRA, Ana Flávia Braun; FREITAS JUNIOR, Miguel Archanjo de. (Orgs.). Norbert Elias em Debate: Usos e Possibilidades de Pesquisa no Brasil. 2020, p. 208-235. Disponível em:

file://C:/Users/R\%C3\%BAbia/Desktop/artigo\%201\%20e\%202/0e030-ebooknorbert-elias-em-debate.pdf. Acesso em: 14 mar. 2021.

Recebido em: 16 de março de 2021. Aceito em: 24 de maio de 2021. Publicado em: 30 de junho de 2021. 